\title{
Prognostic Value of Pre-treatment F-18 FDG PET Metabolic Metrics in Patients with Locally Advanced Carcinoma of the Anus with and without HIV Infection
}

\author{
Ismaheel O. Lawal'; Alfred 0 Ankrah',2; Kgomotso M.G. Mokoala'; Gbenga 0. Popoola3; \\ Chimbabantu A Kaoma'; Alex Maes ${ }^{1,4}$; Neo P. Mokgoro'; Christophe Van de Wiele ${ }^{1,5}$; \\ Mike M. Sathekge ${ }^{1}$ \\ ${ }^{1}$ Department of Nuclear Medicine, University of Pretoria \& Steve Biko Academic Hospital, Pretoria, South Africa; ${ }^{2}$ De- \\ partment of Nuclear Medicine and Molecular Imaging, University Medical Center Groningen \& University of Groning- \\ en, Groningen, The Netherlands; ${ }^{3}$ Department of Epidemiology and Community Health, University of Ilorin, Ilorin, \\ Nigeria; ${ }^{4}$ Department of Nuclear Medicine, AZ Groeninge, Kortrijk, Belgium; ${ }^{5}$ Department of Radiology and Nuclear \\ Medicine, University Ghent, Ghent, Belgium
}

Keywords

F-18 FDG PET, SUV max $_{1}$ MTV, TLG, HIV, carcinoma of the anus

\section{Summary}

Aim: To investigate the prognostic value of F-18 FDG PET metabolic parameters in patients with anal carcinoma with and without human immunodeficiency virus infection (HIV). Methods: Maximum standardized uptake value $\left(S U V_{\text {max }}\right)$, mean standardized uptake value $\left(S_{U V} V_{\text {mean }}\right)$, metabolic tumor volume (MTV) and total lesion glycolysis (TLG) were obtained on F-18 FDG PET/CT images of treatment-naïve patients with locally advanced anal squamous cell carcinoma (ASSC). We compared patients' characteristics and F-18 FDG PET metabolic metrics between the HIV-infected patients and the HIV-uninfected patients. We did a simple Cox regression analysis followed by a multiple Cox regression analysis to determine factors predictive of death. Results: We studied 33 patients including 21 HIV-infected individ-

Correspondence to

Mike M. Sathekge, MD, PhD

Department of Nuclear Medicine,

University of Pretoria and

Steve Biko Academic Hospital,

Private Bag X169, Pretoria 0001 ,

South Africa

Tel: +27 123541794

Fax: +27 123541219

Email: mike.sathekge@up.ac.za uals, mean age $=46.06 \pm 12.59$, female $=16$, males $=17$. Median CD4 count among HIV-infected patients was 400.50 cells $/ \mathrm{mm}^{3}$ (IQR: 304.0-642.25). HIV-infected patients were younger than the HIV-uninfected patients at the time of diagnosis; $38.71 \pm 7.98$ vs. $58.92 \pm 7.88$ respectively, $p<0.001$. No significant difference in the TNM stage and F-18 FDG metabolic parameters between the two groups. In a simple Cox regression analysis, MTV and TLG were significant predictors of death. Following a multiple Cox regression analysis, MTV and SUV ${ }_{\text {mean }}$ were significant predictors of death. The median overall survival was $44.63(95 \%$ Cl: 34.12-55.14) among HIV-infected patients versus 54.65 (95\% Cl: 45.73-63.57) among HIV-uninfected patients, $p=0.415$. Conclusion: HIV-infected patients are diagnosed with ASSC at a younger age compared with HIV-uninfected patients. F-18 FDG PET metabolic metrics especially MTV predicts overall survival in patients with ASCC. There is no difference in the

Prognostischer Wert der F-18 FDG PET metabolischen Aktivität vor Therapie des lokal fortgeschrittenen Anal-Plattenepithelkarzinoms bei HIVpositiven und -negativen Patienten Nuklearmedizin 2018; 57: 190-197 https://doi.org/10.3413/Nukmed-0965-18-03 received: March 17, 2018 accepted: June 25, 2018 overall survival of HIV-infected and HIV-uninfected patients treated similarly for ASSC.

Schlüsselwörter

F-18 FDG PET, SUV max $_{1}$ MTV, TLG, HIV, Analkarzinom

\section{Zusammenfassung}

Ziel: Die Untersuchung der prognostischen Bedeutung der F-18 FDG PET metabolischen Aktivität bei HIV-negativen und positiven Analkarzinom-Patienten. Methoden: Bestimmt wurden maximale standardisierten Uptake-Werte $\left(\right.$ SUV $\left._{\max }\right)$, mittlere standardisierte Uptake-Werte $\left(S_{U} V_{\text {mean }}\right)$, das metabolische Tumorvolumen (MTV) sowie die gesamte Tumorlyse-Glukose (TLG) mittels F-18 FDG $\mathrm{PET} / \mathrm{CT}$ bei behandlungsnaiven Patienten mit lokal fortgeschrittenem Anal-Plattenepithelkarzinom (ASSC). Die Patientencharakteristika und F-18 FDG PET metabolischen Ergebnisse der HIV-positiven und HIV-negativen Patienten wurden verglichen. Eine einfache Cox-Regressionsanalyse gefolgt von einer multiplen Cox-Regressionsanalyse diente der Bestimmung von Faktoren für Tod.

Ergebnisse: Wir untersuchten 33 Patienten, davon 21 HIV-Infizierte, mittleres Alter $=46,06 \pm 12,59$, Frauen $=16$, Männer $=17$. Die mediane CD4-Zahl unter den HIV-Patienten war 400,50Zellen/mm $\mathrm{mm}^{3}$ (IRQ: 304,0-642,25). Die HIV-infizierten Patienten 
waren jünger als die HIV-negativen Patienten zum Zeitpunkt der Diagnose; 38,71 $\pm 7,98$ vs. $58,92 \pm 7,88, p<0,001$. Es gab keinen signifikanten Unterschied in der TNM-Klassifikation und in den F-18 FDG metabolischen Werten zwischen den beiden Gruppen. In einer einfachen Cox-Regressionsanalyse waren MTV und TLG signifikante Prädiktoren für Tod. Das mediane Gersamtüberleben lag bei 44,63 (95\% Cl: 34,12-55,14) unter den HIV-infizierten Patienten vs. $54,65 \quad(95 \% \quad \mathrm{Cl}$ : 45,73-63,57) unter den HIV-negativen Patienten, $p=0,415$.

Schlussfolgerungen: HIV-infizierte Patienten werden in jüngeren Jahren mit ASSC diagnostiziert im Vergleich zu HIV-negativen Patien- ten. F-18 FDG PET metabolische Aktivität, insbesondere MTV, kann das Gesamtüberleben von Patienten mit ASCC vorhersagen. Es gibt keinen Unterschied im Gesamtüberleben von HIV-infizierten und HIV-negativen Patienten bei gleicher Therapie des ASSC.

\section{Introduction}

Anal cancer is a rare malignancy of the gastrointestinal tract with a rising incidence. In the United States, it is projected to account for $0.49 \%$ of new cancer cases in 2018 (1). Squamous cell carcinoma (SCC) accounts for the majority of anal cancers. Factors attributed to the rising incidence of SCC of the anus include human immunodeficiency virus (HIV) infection, human papillomavirus (HPV) infection, smoking, men having sex with men, multiple sexual partners, among others. Immunodeficiency syndrome associated with HIV infection leads to an increase in the incidence and persistence of HPV infection among HIVinfected individuals (2). Infection with high-risk strains of HPV is associated with the presence of high-grade squamous intraepithelial lesions, the precursor lesion for anal squamous cell carcinoma (ASCC) (3).

ASCC is the commonest type of non-acquired immunodeficiency syndrome (AIDS)-defining malignancies (4). There is, however, no consensus yet on the impact of HIV infection on the occurrence of treatment-related toxicities and survival among patients with ASCC. Some studies have reported a higher incidence of toxicity and shorter overall survival with 5-fluorouracil/mitomycin-C (MMC)-based concurrent chemoradiotherapy among HIVinfected patients $(5,6)$, others have reported no difference between HIV-infected and uninfected patients (7-10). Similar overall survival between HIV-infected and HIV-uninfected patients with ASCC but higher chemoradiotherapy-related toxicity has also been reported (11).

Positron emission tomography (PET)/ computed tomography (CT) with F-18 flu- orodeoxyglucose (F-18 FDG) has been shown to demonstrate high diagnostic performance in the staging and re-staging of various malignancies (12-14). In a recent meta-analysis, F-18 FDG PET/CT was found to outperform standalone CT in the evaluation of the primary tumor in patients with anal cancer (15). F-18 FDG PET/CT was found to lead to change in nodal staging in $21 \%$ of patients. F-18 FDG PET metabolic parameters such as maximum standardized uptake value $\left(\mathrm{SUV}_{\max }\right)$, mean standardized uptake value $\left(\mathrm{SUV}_{\text {mean }}\right)$, metabolic tumor volume (MTV) and total lesion glycolysis are a measure of tumor metabolic rate and its biology. They reflect tumor aggressiveness and have been found to predict therapy response and survival in different malignant diseases (16-18). These metabolic parameters have recently been reported in the assessment of the differences in tumor bulk in HIV-infected versus uninfected patients with Hodgkin lymphoma (19). The aim of this study was to determine the prognostic value of $\mathrm{SUV}_{\max }$, $\mathrm{SUV}_{\text {mean }}, \mathrm{MTV}$ and TLG obtained at initial staging in a mixed group of HIV-infected and HIV-uninfected patients with locally advanced squamous cell carcinoma of the anus.

\section{Material and Methods}

\section{Patients}

Patients $\geq 18$ years with histologically confirmed locally advanced (T3/4, or $\mathrm{N} 1 \mathrm{a} / \mathrm{N} 1 \mathrm{~b} / \mathrm{N} 1 \mathrm{c}$ or M disease) squamous cell carcinoma were included in this study. The staging was done using the American Joint Committee on Cancer (AJCC) TNM classification and staging system, $8^{\text {th }}$ Edition (2018). All patients had a baseline F-18
FDG PET/CT before commencing chemo radiotherapy. Patients with T1/T2 disease without nodal or visceral metastasis were excluded. Other patients who were excluded include patients with histological variants other than squamous cell carcinoma, patients without baseline F-18 FDG PET/CT before commencing chemoradiotherapy, patients with a second malignancy, and patients with missing medical records in whom survival analysis could not be done.

In the patients included, their HIV status was determined and recorded. In the HIV-infected patients, the CD 4 count and HIV viral load were documented. We determined whether patients were alive or dead at the time of image analysis. We determined the overall survival (OS) of subjects which was the time from diagnosis to death (in patients who had died) or the time of image analysis.

\section{F-18 FDG PET/CT scan}

Patient preparation for F-18 FDG PET/CT was as done in accordance with international guidelines. All patients had a minimum of 4 hours of fasting. Blood sugar before F-18 FDG injection was less than $7.2 \mathrm{mmol} / \mathrm{L}$ in all cases. The injected activity of F-18 FDG was based on patients' weight using the formula:

[(body weight $\div 10)+1]$ X $37 \mathrm{MBq}$.

We imaged patients after an uptake period of 60 minutes on a Biograph 40 Truepoint PET/CT scanner (Siemens Medical Solution, IL, USA). Oral contrast: $30 \mathrm{~mL}$ of gastrografin (Bayers, Isando, South Africa) diluted in 1 liter of water was given orally over 1 hour before imaging. Intravenous 
contrast: $100 \mathrm{~mL}$ of omnipaque 350 (GE Healthcare, WI, USA) was given intravenously with a scan delay of $80 \mathrm{~s}$. We performed a vertex to mid-thigh CT scan with parameters adjusted for patients' weight $(120 \mathrm{KeV}, 40-150 \mathrm{mAs})$ with a section width of $5 \mathrm{~mm}$ and pitch of 0.8 . PET imaging was acquired in $3 \mathrm{D}$ mode at $3 \mathrm{~min}$ utes per bed position. A separate pelvic image acquisition was done after patients have emptied their urinary bladder. We used CT data for attenuation correction and for delineation of lesions. We performed image reconstruction using ordered subset expectation maximization iterative reconstruction algorithm (4 iterations, eight subsets) followed by post-reconstruc-

Tab. 1 Clinicopathologic characteristics of the patients

\begin{tabular}{|c|c|c|}
\hline Variable & Frequency & Percent \\
\hline \multicolumn{3}{|l|}{ Age (years) } \\
\hline$\leq 40$ & 15 & 45.5 \\
\hline $41-60$ & 14 & 42.4 \\
\hline$>60$ & 4 & 12.1 \\
\hline Mean \pm SD & \multicolumn{2}{|c|}{$46.06 \pm 12.59$} \\
\hline Range & \multicolumn{2}{|c|}{$29-78$} \\
\hline \multicolumn{3}{|l|}{ Gender } \\
\hline Male & 17 & 51.5 \\
\hline Female & 16 & 48.5 \\
\hline \multicolumn{3}{|l|}{ HIV infection } \\
\hline Yes & 21 & 63.6 \\
\hline No & 12 & 36.4 \\
\hline \multicolumn{3}{|l|}{ TNM stage } \\
\hline IIB & 7 & 21.2 \\
\hline IIIA & 2 & 6.1 \\
\hline IIIB & 1 & 6.1 \\
\hline IIIC & 18 & 54.5 \\
\hline IV & 5 & 12.1 \\
\hline \multicolumn{3}{|c|}{ CD4 count (cells/mm³) } \\
\hline Median (IQR) & \multicolumn{2}{|c|}{$400.50(304.00-642.25)$} \\
\hline Range & \multicolumn{2}{|c|}{$76.00-978.00$} \\
\hline \multicolumn{3}{|c|}{ Viral load (copies/mL) } \\
\hline LDL & 14 & 42.4 \\
\hline Median (IQR) & \multicolumn{2}{|c|}{$303.50(74.00-533.00)$} \\
\hline Range & \multicolumn{2}{|c|}{$74.00-533.00$} \\
\hline
\end{tabular}

tion filtering with a Gaussian filter at $5.0 \mathrm{~mm}$ FWHM.

\section{Image analysis}

Reconstructed images were displayed as maximum intensity projection image, $\mathrm{PET}$, $\mathrm{CT}$, and fused PET/CT in the axial, coronal and sagittal planes on a dedicated workstation equipped with a syngo software (Siemens Medical Solutions, IL, USA). A semi-automatic spherical volume of interest (VOI) was drawn encircling the primary lesion in the anus using an SUV threshold of 2.5 and a 3D isocontour of $41 \%$. The VOI was manually adjusted to exclude physiologic areas of uptake adjacent to the primary lesion. The $\mathrm{SUV}_{\max }$, $\mathrm{SUV}_{\text {mean }}$, and MTV of the primary lesion in each patient were recorded. TLG was manually computed by multiplying the MTV by $\mathrm{SUV}_{\text {mean }}$

Two Nuclear Medicine Physicians with about a decade experience interpreting F-18 FDG PET/CT each determined the presence of nodal and distant metastases in a prospective analysis of a retrospective set of data. Disagreements were resolved by consensus.

\section{Statistical analyses}

We used descriptive statistics (mean, median, standard deviation and interquartile range) to describe the baseline clinicopathologic characteristics of the study population. We used Chi-square test to determine if significant differences exist between the HIV-infected and HIV-uninfected patients with regards to age, gender, presence or absence of nodal or visceral metastasis, TNM stage of the disease, and the proportion of patients alive at the time of analysis. We used Mann Whitney U test to test for differences in $\mathrm{SUV}_{\text {max }}, \mathrm{SUV}_{\text {mean }}$, MTV, and TLG between the two groups. We performed a simple Cox regression to determine which of age, gender, the presence of nodal or visceral metastasis, TNM stage, presence or absence of HIV infection, $\mathrm{SUV}_{\max }, \mathrm{SUV}_{\text {mean }}, \mathrm{MTV}$, and TLG will predict overall survival. We performed a multiple Cox regression [backward stepwise (Likelihood Ratio) method] of selected variables with $\mathrm{p}<0.25$ on simple Cox regression (nodal metastasis, $\mathrm{SUV}_{\text {max }}$, $\mathrm{SUV}_{\text {mean }}, \mathrm{MTV}$, and TLG) and those with probable clinical significance (HIV infection, TNM stage). We constructed survival curves to plot the proportion of surviving patients during follow-up.

\section{Results}

A total of 33 patients with locally advanced squamous cell carcinoma met the inclusion criteria and were included in this study, mean age $\pm \mathrm{SD}=46.06 \pm 12.59$ years, male $=$ $17(51.5 \%)$, females $=16(48.5 \%)$. Of these patients, $63.67 \%(21 / 33)$ were HIV-infected. All HIV-infected patients were on combination antiretroviral therapy (cART) at the time of diagnosis of ASCC with a median CD 4 count of 400.5 cells $/ \mathrm{mm}^{3}$ (Interquartile range, $\mathrm{IQR}=304.00-642.25)$. Out of $21 \mathrm{HIV}$-infected patients, 14 had no detectable HIV viremia. The median HIV viral load among seven patients with detected HIV viremia was 303.50 copies $/ \mathrm{mL}$ (range $=74.00-533.00$ ). More than half of the patients $(54.5 \%)$ had AJCC stage IIIC disease. Distant metastasis was present in five patients (stage IV disease). $>$ Table 1 shows the clinic-pathologic distribution of the study population.

\section{Comparison of clinical, pathologic and F-18 FDG PET metabolic par- ameters between HIV-infected and HIV-uninfected patients}

The HIV-infected patients were significantly younger at the time of diagnosis of ASCC compared with the HIV-uninfected patients, median age at diagnosis HIV-infected versus uninfected of 37.00 years versus 56.50 years respectively, $\mathrm{p}<0.001$. We found no significant difference in the gender distribution between the two groups. Fifteen HIV-infected patients had nodal metastases compared with six patients without HIV infection $(p=0.274)$. Among the five patients with visceral metastases, two were HIV positive while three were not. The median $S U V_{\max }$ and SUV $_{\text {mean }}$ were slightly higher among HIVinfected patients compared with HIV-uninfected patients, but the differences did not reach statistical significance. Con- 
versely, median MTV and TLG were somewhat higher among HIV-uninfected compared with the HIV-infected patients $(\mathrm{p}>0.05)$. $>$ Table 2 shows the differences in the clinicopathologic and F-18 FDG PET metabolic parameters between HIVinfected and HIV-uninfected patients with ASCC. $>$ Figures 1 and 2 show representative F-18 FDG PET/CT images of HIVinfected and HIV-uninfected patients with ASCC.

\section{Predictors of mortality}

We performed a simple cox regression analysis to determine the factors predictive of mortality among patients with ASCC ( Table 3) and found MTV (hazard ratio, $\mathrm{HR}=1.008 ; 95 \%$ confidence interval, $\mathrm{CI}$ : $1.001-1.016 ; \quad \mathrm{p}=0.031)$ and TLG $(\mathrm{HR}=1.001 ; \quad 95 \% \quad \mathrm{CI}: \quad 1.000-1.002$; $\mathrm{p}=0.021)$ to significantly predict patients dying from their cancer. The other two F-18 FDG PET metabolic parameters were not significant predictors of mortality. Similarly, clinicopathologic factors such as age $(\mathrm{HR}=0.987 ; 95 \% \mathrm{CI}: 0.941-1.035)$, gender $(\mathrm{HR}=1.394 ; 95 \% \mathrm{CI}: 0.441-4.409)$, presence of nodal metastasis $(\mathrm{HR}=3.195$; 95\% CI: $0.699-14.613)$, presence of visceral metastasis $(\mathrm{HR}=1.806 ; 95 \% \mathrm{CI}$ : $0.487-6.694)$, and presence of HIV infection $(\mathrm{HR}=1.626 ; 95 \% \mathrm{CI}: 0.487-5.430)$ were also not significant in predicting mortality, $\mathrm{p}>0.05$.

In our multiple Cox regression analysis ( Table 4), MTV remained a significant predictor mortality in patients with ASCC $(\mathrm{HR}=1.013, \quad 95 \% \quad \mathrm{CI}: \quad 1.003-1.022)$, $\mathrm{p}=0.010$. TLG was no longer a significant predictor of mortality. $\mathrm{SUV}_{\text {mean }}$ which was not a significant predictor of mortality in simple Cox regression analysis became significantly predictive of mortality following multiple Cox regression $(\mathrm{HR}=2.428,95 \%$ CI: $1.22-4.817), \mathrm{p}=0.011$. Other factors such age, gender, the presence of nodal metastasis, the presence of visceral metastasis and presence of HIV infection remained statistically not significant, $\mathrm{p}>0.05$.

\section{Survival analysis}

After a median follow-up period of 37 months (range: 5-66), 12 deaths had oc-
Tab. 2 Differences in clinic-pathologic and F-18 FDG PET parameters between HIV-infected and HIV-uninfected patients with anal squamous cell carcinoma

\begin{tabular}{|c|c|c|c|c|c|}
\hline \multirow[t]{2}{*}{ Variable } & \multicolumn{3}{|l|}{ HIV infection } & \multirow[b]{2}{*}{$\mathrm{X}^{2}$} & \multirow[b]{2}{*}{$p$ value } \\
\hline & $\begin{array}{l}\text { Positive } \\
\text { n (\%) }\end{array}$ & $\begin{array}{l}\text { Negative } \\
\text { n (\%) }\end{array}$ & $\begin{array}{l}\text { Total } \\
\text { N (\%) }\end{array}$ & & \\
\hline \multicolumn{6}{|c|}{ Age (years) } \\
\hline$\leq 40$ & $15(71.4)$ & $0(0.0)$ & $15(45.5)$ & $13.384^{Y}$ & 0.001 \\
\hline $41-60$ & $6(28.6)$ & $8(66.7)$ & $14(42.4)$ & & \\
\hline$>60$ & $0(0.0)$ & $4(33.3)$ & $4(12.1)$ & & \\
\hline Mean \pm SD & $38.71 \pm 7.98$ & $58.92 \pm 7.88$ & & & \\
\hline $\begin{array}{l}\text { Median } \\
\text { (IQR) }\end{array}$ & $\begin{array}{l}37.00 \\
(34.00-41.00)\end{array}$ & $\begin{array}{l}56.50 \\
(52.50-62.75)\end{array}$ & & $15.000^{U}$ & $<0.001$ * \\
\hline \multicolumn{6}{|l|}{ Gender } \\
\hline Male & $11(52.4)$ & $6(50.0)$ & $17(51.5)$ & 0.017 & 0.895 \\
\hline Female & $10(47.6)$ & $6(50.0)$ & $16(48.5)$ & & \\
\hline \multicolumn{6}{|c|}{ Nodal metastasis } \\
\hline Present & $15(71.4)$ & $6(50.0)$ & $21(63.6)$ & 1.515 & 0.274 \\
\hline Absent & $6(28.6)$ & $6(50.0)$ & $12(36.4)$ & & \\
\hline \multicolumn{6}{|c|}{ Visceral metastasis } \\
\hline Present & $2(9.5)$ & $3(25.0)$ & $5(15.2)$ & 1.423 & 0.328 \\
\hline Absent & $19(90.5)$ & $9(95.0)$ & $28(84.8)$ & & \\
\hline \multicolumn{6}{|l|}{ TNM stage } \\
\hline IV & $2(9.5)$ & $3(25.0)$ & $4(12.1)$ & $1.344^{Y}$ & 0.246 \\
\hline I-III & $20(90.5)$ & $9(75.0)$ & $29(87.9)$ & & \\
\hline \multicolumn{6}{|l|}{ Survival } \\
\hline Alive & $13(61.9)$ & $8(66.7)$ & $21(63.6)$ & 0.075 & 1.000 \\
\hline Dead & $8(38.1)$ & $4(33.3)$ & $12(36.4)$ & & \\
\hline \multicolumn{6}{|l|}{$\mathrm{SUV}_{\max }$} \\
\hline $\begin{array}{l}\text { Media } \\
\text { (IQR) }\end{array}$ & $\begin{array}{l}16.85 \\
(13.38-25.11)\end{array}$ & $\begin{array}{l}13.15 \\
(8.28-19.31)\end{array}$ & & $65.000^{U}$ & 0.124 \\
\hline \multicolumn{6}{|l|}{ SUV $_{\text {mean }}$} \\
\hline $\begin{array}{l}\text { Median } \\
\text { (IQR) }\end{array}$ & $\begin{array}{l}6.50 \\
(4.90-8.08)\end{array}$ & $\begin{array}{l}5.12 \\
(3.36-6.99)\end{array}$ & & $66.000^{U}$ & 0.135 \\
\hline \multicolumn{6}{|l|}{ MTV } \\
\hline $\begin{array}{l}\text { Median } \\
\text { (IQR) }\end{array}$ & $\begin{array}{l}153.48 \\
(78.08-237.30)\end{array}$ & $\begin{array}{l}172.27 \\
(36.98-243.13)\end{array}$ & & $93.000^{U}$ & 0.758 \\
\hline \multicolumn{6}{|l|}{ TLG } \\
\hline $\begin{array}{l}\text { Median } \\
\text { (IQR) }\end{array}$ & $\begin{array}{l}857.53 \\
(513.34-1918.50)\end{array}$ & $\begin{array}{l}1086.78 \\
(106.42-1281.49)\end{array}$ & & $82.000^{U}$ & 0.551 \\
\hline
\end{tabular}

$\mathrm{X}^{2}$ : Chi-square test; Y: Yates Corrected Chi-square; U: Mann Whitney U test; HIV: Human Immunodeficiency Virus; SUVmax: maximum Standardized Uptake Value; SUVmean: mean Standardized Uptake Value; MTV: Metabolic Tumor Volume; TLG: Total Lesion Glycolysis; * : p-value $<0.05$

curred while 21 patients were alive includ- a lower median survival among HIV-ining $13 \mathrm{HIV}$-infected patients and $8 \mathrm{HIV}$ - fected patients compared with HIV-uninuninfected patients ( $\triangleright$ Table 2). We found fected patients, 44.63 months (95\% CI: 


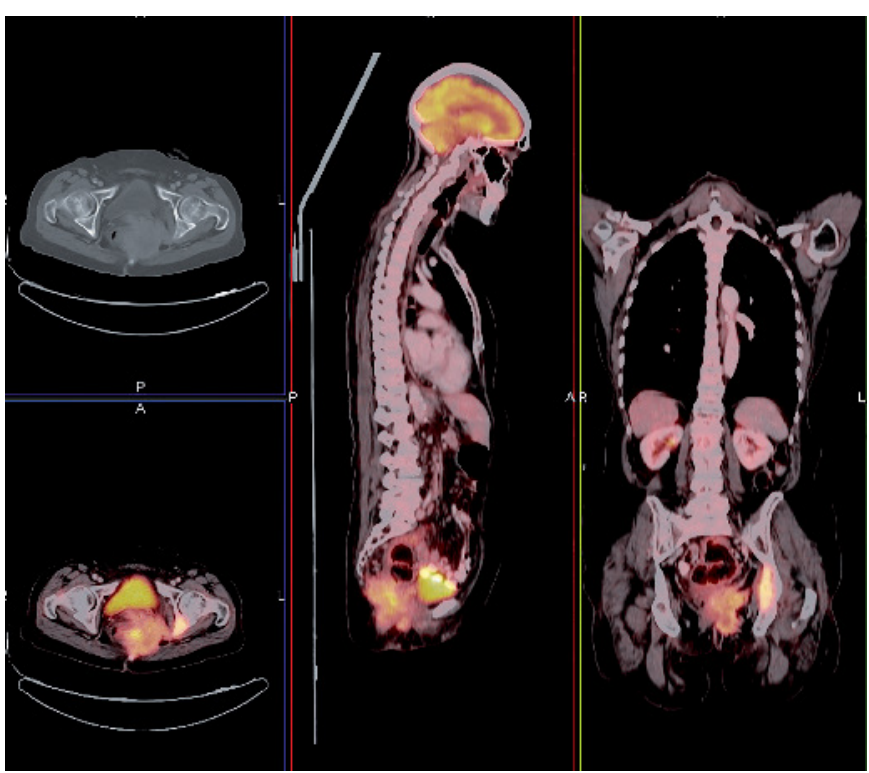

Fig. 1

F-18 FDG PET/CT images of a 58-year-old HIV negative male with squamous cell carcinoma of the anus show a large anal mass with invasion into the adjacent left pelvic bone.

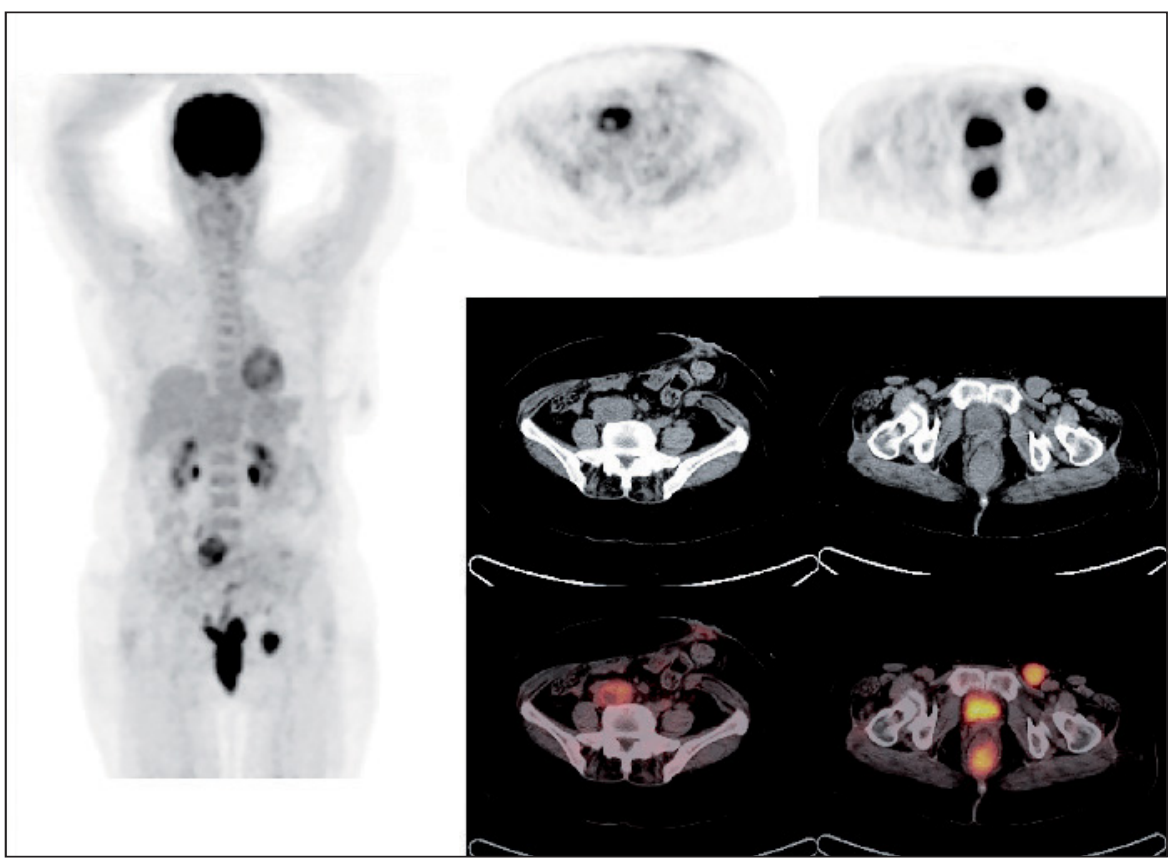

Fig. 2 F-18 FDG PET/CT images of a 32-year-old HIV positive female with squamous cell carcinoma show the primary anal mass with left inguinal and right iliac nodal metastases.

$34.12-55.14)$ versus 54.65 months (95\% CI: 45.73-63.57), $\rightarrow$ Table 5. This difference was however not statistically significant. $\gg$ Figure 3 shows the Kaplan-Meier survival curves demonstrating proportion of patients who remained alive during the follow-up period.

\section{Discussion}

This study evaluated the predictive role of F-18 FDG PET metabolic parameters in a mixed group of HIV-infected and HIV-uninfected patients with locally advanced squamous cell carcinoma of the anus on the overall survival and found that HIV-infected patients are diagnosed at much earlier age compared with HIV-uninfected pa- tients, by an average of almost 20 years. HIV infection causes with chronic immunosuppression which predisposes patients to persistent infection with HPV, an oncogenic virus which predisposes to the development of high grade squamous intraepithelial lesions, the precursor lesion of ASCC (2). Factors which predisposes to HPV infection or are themselves associated with ASSC are prevalent among HIV-infected individuals. Such factors include men having sex with men and smoking $(20,21)$. Lokko et al. also found HIV-infected patients in their study cohorts significantly younger than HIV-uninfected patients by an average of about 14 years (8). Others have similarly reported the diagnosis of ASCC at a younger age in HIV-infected patients $(6,9,11)$.

In our cohort of patients, we did not find any significant difference between HIV-infected and HIV-uninfected patients regarding $S \mathrm{SVV}_{\max }, S \mathrm{SUV}_{\text {mean }}, \mathrm{MTV}$, and TLG. This may suggest that HIV infection does not impact on disease burden in patients with ASSC. Since these F-18 FDG PET metabolic parameters have been reported to have implications on therapy outcome and survival, our findings appear to support findings from a study that has reported no difference in the treatment outcome and overall survival between HIV-uninfected patients and other patients with ASSC without HIV infection (8). Similarly, HIV-infected patients were not significantly different from the HIV-uninfected group in our study with regards gender and the TNM stage of the disease.

F-18 FDG PET metabolic parameters are a measure of tumor biology which reflects tumor metabolism. These parameters have been found to predict therapy outcome and impact on survival in different malignancies (22-24). In a simple Cox regression analysis, we found MTV and TLG to significantly predict mortality among patients with ASCC. These volumetric metrics assess the viable volume of a tumor bulk rather than the whole tumor burden which may include regions of necrosis and fibrosis, especially in large tumor mass. They are therefore better metrics to predict tumor biology than anatomic measurement of gross tumor volume. MTV remained a significant predictor of mortality 
after a multiple Cox regression analysis while TLG was not. Bazan et al., in a retrospective review of 39 patients with ASSC, also found MTV as a significant predictor of survival (25). SUV $\max$ is the pixel with the highest F-18 FDG uptake within the tumor volume and may not reflect the global metabolic status of the tumor. We did not find $\mathrm{SUV}_{\max }$ as a significant predictor of mortality. This is in agreement with the finding of a recent larger study that also did not find pre-treatment $\mathrm{SUV}_{\max }$ as a significant predictor of survival in a multivariate analysis (26). Kidd et al. however reported $\mathrm{SUV}_{\text {max }}$ as a significant predictor of lymph node metastasis and survival (27).

The impact of HIV infection on treatment outcome and survival has been a subject of great interest. It is important to determine if the presence of HIV infection impact negatively on the outcome of treatment or mortality among patients with HIV-associated malignancies. The interest in this subject is geared to select optimum treatment strategy for these cancers. We found no difference in the overall survival of HIV-infected patients and patients without the infection in our cohorts. This is in agreement with the more recent studies in the literature reporting an absence of any negative impact of HIV infection on the overall survival of patients with ASSC (7-11). Based on these, patients with ASCC are now being treated similarly regardless of their HIV status. A similar finding has been demonstrated in other nonAIDS defining cancers including as Hodgkin lymphoma which is now considered to have the prognosis irrespective of the patient's HIV status (28-30).

Our study has many the limitations, the most significant of which is the modest study population. This is related to the rarity of anal cancer and the strict inclusion criteria. We only studied patients with locally advanced disease and excluded patients with a small primary lesion. This was done believing that the impact of partial volume effect will have a more significant effect on the F-18 FDG PET metabolic parameters in small tumors. We also excluded patients with other histological variants of carcinoma of the anus other than squamous cell cancer. We only evaluated for the impact on F-18 FDG PET metabolic met-

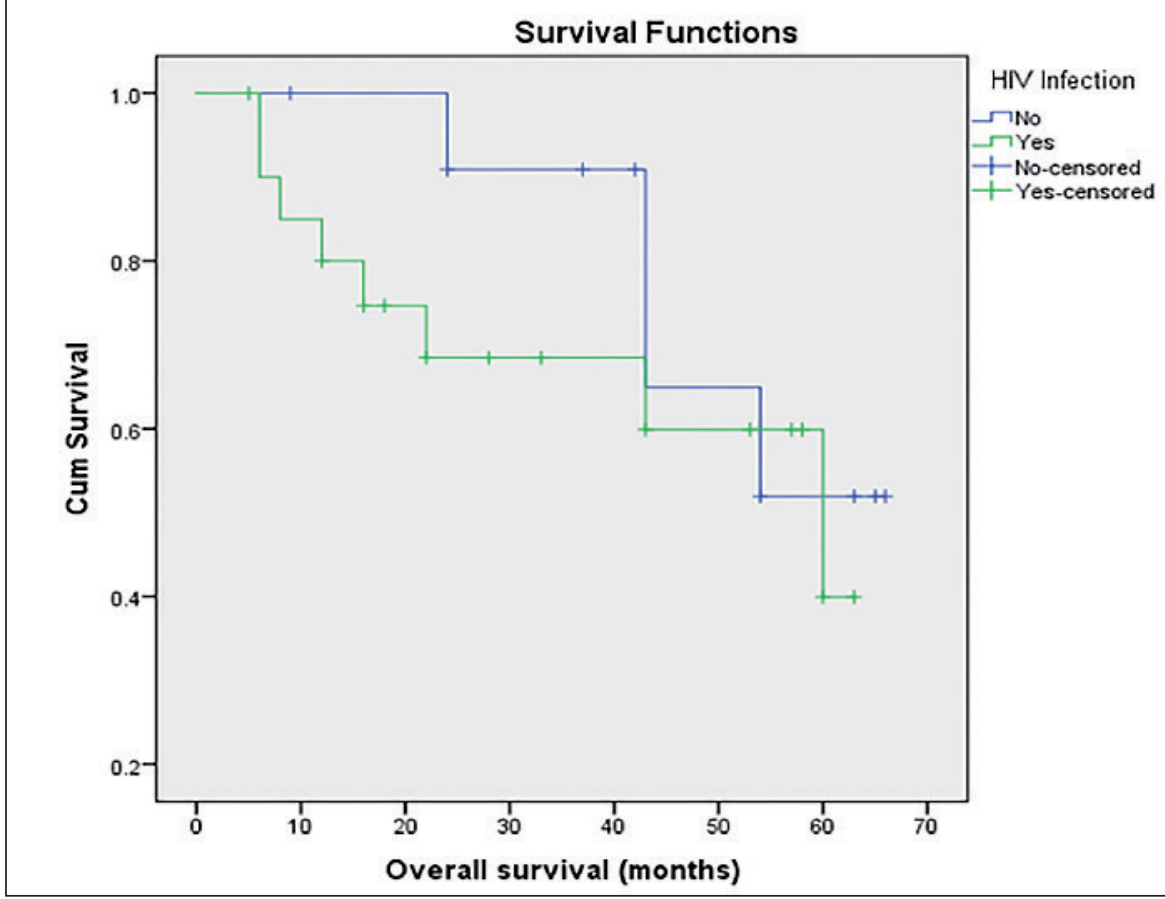

Fig. 3 Kaplan-Meier curves showing the proportion of surviving patients during follow-up.

Tab. 3

Simple Cox regression to determine the factors predictive of mortality

\begin{tabular}{|c|c|c|c|}
\hline Variables & b (SE) & Crude HR $(95 \% \mathrm{Cl})$ & $p$ value \\
\hline $\begin{array}{l}\text { Age } \\
\text { (years) }\end{array}$ & $-0.013(0.024)$ & $0.987(0.941-1.035)$ & 0.587 \\
\hline \multicolumn{4}{|l|}{ Gender } \\
\hline Female & & 1 & \\
\hline Male & $0.332(0.588)$ & $1.394(0.441-4.409)$ & 0.572 \\
\hline \multicolumn{4}{|c|}{ Nodal metastasis } \\
\hline Absent & & 1 & \\
\hline Present & $1.162(0.776)$ & $3.195(0.699-14.613)$ & 0.134 \\
\hline \multicolumn{4}{|c|}{ Visceral metastasis } \\
\hline Absent & & 1 & \\
\hline Present & $0.591(0.668)$ & $1.806(0.487-6.694)$ & 0.376 \\
\hline \multicolumn{4}{|c|}{ TNM stage } \\
\hline I-III & & 1 & \\
\hline IV & $0.591(0.668)$ & $1.806(0.487-6.694)$ & 0.376 \\
\hline \multicolumn{4}{|c|}{ HIV infection } \\
\hline No & & 1 & \\
\hline Yes & $0.486(0.615)$ & $1.626(0.487-5.430)$ & 0.429 \\
\hline SUV $_{\text {max }}$ & $0.046(0.038)$ & $1.047(0.972-1.129)$ & 0.228 \\
\hline $\mathrm{SUV}_{\text {mean }}$ & $0.194(0.125)$ & $1.214(0.951-1.552)$ & 0.120 \\
\hline MTV & $0.008(0.004)$ & $1.008(1.001-1.016)$ & $0.031 *$ \\
\hline TLG & $0.001(0.000)$ & $1.001(1.000-1.002)$ & $0.021^{*}$ \\
\hline
\end{tabular}

HR: Hazard Ratio; HIV: Human Immunodeficiency Virus; SUV max $_{\text {: maximum }}$ Standardized Uptake Value; SUV $_{\text {mean }}$ : mean Standardized Uptake Value; MTV: Metabolic Tumor Volume; TLG: Total Lesion Glycolysis; * : p value $<0.05$ 
Tab. 4 Multiple Cox regression analysis of predictors of survival

\begin{tabular}{|c|c|c|c|c|}
\hline Variables & Crude $\mathrm{HR}^{\mathrm{a}}(95 \% \mathrm{Cl})$ & $p$ value & Adjusted $\mathrm{HR}^{\mathrm{b}}(95 \% \mathrm{CI})$ & $p$ value \\
\hline Age (years) & $0.987(0.941-1.035)$ & 0.587 & & \\
\hline \multicolumn{5}{|l|}{ Gender } \\
\hline Female & 1 & & & \\
\hline Male & $1.394(0.441-4.409)$ & 0.572 & & \\
\hline \multicolumn{5}{|c|}{ Nodal metastasis } \\
\hline Absent & 1 & & & \\
\hline Present & $3.195(0.699-14.613)$ & 0.134 & & \\
\hline \multicolumn{5}{|c|}{ Visceral metastasis } \\
\hline Absent & 1 & & & \\
\hline Present & $1.806(0.487-6.694)$ & 0.376 & & \\
\hline \multicolumn{5}{|l|}{ TNM stage } \\
\hline$|-|||$ & 1 & & & \\
\hline IV & $1.806(0.487-6.694)$ & 0.376 & & \\
\hline \multicolumn{5}{|c|}{ HIV infection } \\
\hline No & 1 & & & \\
\hline Yes & $1.626(0.487-5.430)$ & 0.429 & & \\
\hline SUV $_{\max }$ & $1.047(0.972-1.129)$ & 0.228 & $0.800(0.615-1.040)$ & 0.096 \\
\hline $\mathrm{SUV}_{\text {mean }}$ & $1.214(0.951-1.552)$ & 0.120 & $3.231(1.207-8.648)$ & $0.020^{*}$ \\
\hline MTV & $1.008(1.001-1.016)$ & $0.031^{*}$ & $1.028(1.003-1.054)$ & $0.029^{*}$ \\
\hline TLG & $1.001(1.000-1.002)$ & $0.021^{*}$ & $0.998(0.994-1.001)$ & 0.187 \\
\hline
\end{tabular}

a: Simple Cox proportional hazard regression; b: Multiple Cox proportional hazard ratio HR: Hazard risk of death; HIV: Human Immunodeficiency Virus; SUVmax: maximum Standardized Uptake Value; SUVmean: mean Standardized Uptake Value; MTV: Metabolic Tumor Volume; TLG: Total Lesion Glycolysis; * : p value $<0.05$

Tab. 5 Difference between the median time of death of patients with carcinoma of anus based on HIV infection

\begin{tabular}{|c|c|c|c|c|c|}
\hline Variable & $\mathbf{n}$ & Death (\%) & Median $(95 \% \mathrm{Cl})$ (months) & $\log _{\operatorname{Rank}^{\mathrm{a}}}(\mathrm{df})$ & $\mathrm{p}$-value \\
\hline \multicolumn{6}{|c|}{ HIV infection } \\
\hline Yes & 21 & $8(38.1)$ & $44.63(34.12-55.14)$ & $0.665(1)$ & 0.415 \\
\hline No & 12 & $4(33.3)$ & $54.65(45.73-63.57)$ & & \\
\hline
\end{tabular}

a Kaplan-Meier analysis; HIV: Human Immunodeficiency Virus

rics on overall survival. The impact of these metabolic metrics on other treatment outcomes such as treatment-related toxicity, event-free survival, etc. were not evaluated for in our study.

\section{Conclusion}

ASSC is diagnosed at a much younger age in HIV-infected patients. The burden of

\section{Conflict of interest}

The authors declare that they have no conflicts of interest.

\section{References}

1. Siegel RL, Miller KD, Jemal A. Cancer Statistics, 2018. CA Cancer J Clin 2018; 68: 7-30.

2. Combes JD, Heard I, Poizot-Martin I, et al. Prevalence and risk factors for anal human papillomavirus infection in HIV-positive men having sex with men. J Infect Dis. Epub ahead of print on Jan 31, 2018. doi: 10.1093/infdis/jiy059.

3. Rovelli C, Poli A, Galli L, et al. Presence of multiple genotypes in subjects with HPV-16 infection is highly associated with anal squamous intraepithelial lesions in HIV-1 infected males. PLoS One 2017; 12: e0186367. doi: 10.1371/journal.pone.0186367.

4. Mahale P, Engels EA, Coghill AE, Kahn AR, Shiels MS. Cancer Risk in Older Persons Living With Human Immunodeficiency Virus Infection in the United States. Clin Infect Dis. 2018 Epub ahead of print. doi: 10.1093/cid/ciy012.

5. Oehler-Janne C, Seifert B, Lutolf UM, et al. Local tumor control and toxicity in HIV-associated anal carcinoma treated with radiotherapy in the era of antiretroviral therapy. Radiat Oncol 2006; 1: 29.

6. Grew D, Bitterman D, Leichman CG, et al. HIV Infection Is Associated With Poor Outcomes for Patients With Anal Cancer in the Highly Active Antiretroviral Therapy Era. Dis Colon Rectum 2015; 58: 1130-1136

7. Pappou EP, Magruder JT, Fu T, et al. Prognostic and Predictive Clinicopathologic Factors of Squamous Anal Canal Cancer in HIV-Positive and HIV-Negative Patients: Does HAART Influence Outcomes? World J Surg 2018; 42: 876-883.

8. Lokko C, Turner J, Yoo W, et al. Anal Squamous Cell Carcinoma in African Americans with and without HIV: A comparative Study. J Cancer Epidemiol Treat 2015; 1: 6-10.

9. White EC, Khodayaris B, Erickson KT, Lien WW, Hwang-Graziano J, Rao AR. Comparison of Toxicity and Treatment Outcomes in HIV-positive Versus HIV-negative Patients With Squamous Cell Carcinoma of the Anal Canal. Am J Clin Oncol 2017; 40: 386-392.

10. Fraunholz I, Rabeneck D, Gerstein J, et al. Concurrent chemoradiotherapy with 5-fluorouracil and mitomycin $\mathrm{C}$ for anal carcinoma: are there differences between HIV-positive and HIV-negative patients in the era of highly active antiretroviral therapy? Radiother Oncol 2011; 98: 99-104.

11. Oehler-Jänne $C$, Huguet $F$, Provencher $S$, et al. HIV-specific Differences in Outcome of Squamous Cell Carcinoma of the Anal Canal: A Multicentric Cohort Study of HIV-Positive Patients Receiving Highly Active Antiretroviral Therapy. J Clin Oncol 2008; 26: 2550-2557.

12. Lawal I, Lengana T, Ololade K, et al. ${ }^{18} \mathrm{~F}-\mathrm{FDG}$ PET/ $\mathrm{CT}$ in the detection of asymptomatic malignant melanoma recurrence. Nukleamedizin 2017; 56: 83-89. 
13. Lee JY, Choi JY, Heo JH, et al. Prognostic significance of volume-based ${ }^{18} \mathrm{~F}-\mathrm{FDG}$ PET/CT parameter in patients with surgically resected nonsmall cell lung cancer. Nukleamedizin 2016; 55 : $7-14$.

14. An Y-S, Lee DH, Yoon J-K, et al. Diagnostic performance of ${ }^{18} \mathrm{~F}$-FDG PET/CT, ultrasonography and MRI. Nukleamedizine. 2014;53: 89-94.

15. Jones M, Hruby G, Solomon M, Rutherford N, Martin J. The role of FDG-PET in the Initial Staging and Response Assessment of Anal Cancer: A Systematic Review and Meta-analysis. Ann Surg Oncol 2015; 22: 3574-3581.

16. Liang Y, Li X, Wan H, et al. Prognostic Value of Volume-Based Metabolic Parameters Obtained by ${ }^{18}$ F-FDG-PET/CT in Patients With Locally Advanced Squamous Cell Cervical Carcinoma. J Comput Assist Tomogr. 2018. Epub ahead of print. doi: 10.1097/RCT.0000000000000708.

17. Ngeow JYY, Quek RHH, Ng DCE, et al. High SUV uptake on FDG-PET/CT predicts for an aggressive $\mathrm{B}$-cell lymphoma in a prospective study of primary FDG-PET/CT staging in lymphoma. Ann. Oncol 2009; 20: 1543-1547.

18. Van de Wiele C, Kruse V, Smeets P, et al. Predictive and prognostic value of metabolic tumour volume and total lesion glycolysis in solid tumours. Eur J Nucl Med Mol Imaging 2013; 40: 290-301.

19. Lawal IO, Nyakale NE, Harry LM, et al. The role of F-18 FDG PET/CT in evaluating the impact of
HIV infection on tumor burden and therapy outcome in patients with Hodgkin lymphoma. Eur Nucl Med Mol Imaging 2017; 44: 2025-2033.

20. Wieland U, Hellmich M, Wetendorf J, et al. Smoking and anal high-risk human papillomavirus DNA loads in HIV-positive men who have sex with men. Int J Med Microbiol 2015; 305: 689-696.

21. Lin C, Franceschi S, Clifford GM. Human papillomavirus types from infection to cancer in the anus, according to sex and HIV status: a systematic review and meta-analysis. Lancet Infect Dis 2018; 18: 198-206.

22. Zhang H, Wrobblewski K, Liao S, et al. Prognostic value of metabolic tumor burden from(18)F-FDG PET in surgical patients with non-small-cell lung cancer. Acad Radiol 2013; 20: 32-40.

23. Huang $\mathrm{Y}$, Feng $\mathrm{M}, \mathrm{He} \mathrm{Q}$, et al. Prognostic value of pretreatment ${ }^{18} \mathrm{~F}$-FDG PET-CT for nasopharyngeal carcinoma patients. Medicine (Baltimore) 2017; 96: e6721. doi 10.1097/MD.0000000000006721.

24. Hwang SH, Cho A, Yun M, Choi YD, Rha SY, Kang WJ. Prognostic Value of Pretreatment Metabolic Tumor Volume and Total Lesion Glycolysis Using ${ }^{18}$ F-FDG PET/CT in Patients With Metastatic Renal Cell Carcinoma Treated With Anti-Vascular Endothelial Growth Factor-Targeted Agents. Clin Nucl Med 2017; 42: e235-e241.

25. Bazan JG, Koong AC, Kapp DS, et al. Metabolic tumor volume predicts disease progression and survival in patients with squamous cell carcinoma of the anal canal. J Nucl Med 2013; 54: 27-32.

26. Cardenas ML, Spencer CR, Markovina S, et al. Quantitative FDG-PET/CT predicts local recurrence and survival for squamous cell carcinoma of the anus. Adv Radiat Oncol 2017; 2: 281-287.

27. Kidd EA, Dehdashti F, Siegel BA, Grigsby PW. Anal cancer maximum F-18 fluorodeoxyglucose uptake on positron emission tomography is correlated with prognosis. Radiother Oncol 2010; 95: 288-291.

28. Montoto S, Shaw K, Okosun J, et al. HIV Status Does Not Influence Outcome in Patients With Classical Hodgkin Lymphoma Treated With Chemotherapy Using Doxorubicin, Bleomycin, Vinblastine, and Dacarbazine in the Highly Active Antiretroviral Therapy Era. J Clin Oncol 2012; 30: 4111-4116.

29. Besson C, Lancar R, Prevot S, et al. High Risk Features Contrast With Favorable Outcomes in HIVassociated Hodgkin Lymphoma in the Modern cART Era, ANRS CO16 LYMPHOVIR Cohort. Clin Infect Dis 2015; 61: 1469-1475.

30. Soriqué M, García O, Tapia G, et al. HIV-infection has no prognostic impact on advanced-staged Hodgkin Lymphoma. AIDS 2017; 31: 1445-1449. 